UNIVERSIDADE ESTADUAL DE FEIRA DE SANTANA

Autorizada pelo Decreto Federal $n^{\circ} 77.496$ de 27/04/76

Recredenciamento pelo Decreto $n^{\circ} 17.228$ de $25 / 11 / 2016$

PPPG

PRÓ-REITORIA DE PESQUISA E PÓS-GRADUAÇÃO

COORDENAÇÃO DE INICIAÇÃO CIENTÍFICA

XXIII SEMINÁRIO DE INICIACC̃̃O CIENTÍFICA DA UEFS

SEMANA NACIONAL DE CIENTÍFICA E TECNOLÓGICA - 2019

\title{
O PROJETO EDUCAÇÃO PATRIMONIAL E ARTÍSTICA (EPA) COMO FORMA DE (RE) CONHECIMENTO DO PATRIMÔNIO HISTÓRICO, CULTURAL E ARTÍSTICO DE FEIRA DE SANTANA - BA
}

\author{
LEONARDO JUSTINO SANTANA ${ }^{\mathbf{1}}$; JACKLINE SILVA LOPES ${ }^{2}$; \\ 1. Bolsista PEVIC/UEFFS, Graduando em Licenciatura em História, Universidade Estadual de Feira de Santana, e- \\ mail: leonardojustinosantana@mail.com \\ 2. Orientador, Departamento de Educação, Universidade Estadual de Feira de Santana, e-mail: \\ jack.lopes.lacerda@gmail.com
}

PALAVRAS-CHAVE: Educação, Patrimônio e Ensino de História

\section{INTRODUÇÃO}

“A Educação Patrimonial é um processo permanente e sistemático centrado no patrimônio cultural, como instrumento de afirmação da cidadania. Objetiva envolver a comunidade na gestão do Patrimônio, pelo qual ela também é responsável, levando-a apropriar-se e a usufruir dos bens e valores que o constituem. " (HORTA, 2000).

Nesse sentido, a educação patrimonial é pensada como um instrumento de constituição da identidade, do entendimento do que compõe um patrimônio cultural, da valorização da cultura e da sociedade e, por isso, não deve servir apenas para a promoção e difusão de conhecimentos acumulados no campo técnico da preservação do patrimônio cultural, mas deve ir muito além. (SOARES, 2003).

Nesse sentido, faz-se necessário trabalhar educação patrimonial em diversos espaços de educação, estendendo às amplas áreas de conhecimento, por tratar-se de uma temática que está diretamente ligada a questão da identidade e memória cultural de diversos povos e lugares. Enquanto estudiosos da história, é importante incentivarmos debates e lutas pela valorização e perpetuação da memória dos diversos patrimônios culturais que falam muito da história da nossa sociedade. Isto porque, "a educação patrimonial no ensino de história possibilita a formação de indivíduos capazes de conhecer e ampliar a consciência histórica, além de dar significado a sua própria memória cultural"

\section{MATERIAL E MÉTODOS OU METODOLOGIA}


Os sujeitos da pesquisa foram os professores de história do Centro Integrado de Educação Assis Chateaubriand responsáveis pela aplicação do projeto EPA, além dos estudantes das turmas de primeiro ano do ensino médio que participarão da aplicação do EPA no ano de 2018.

O universo da pesquisa será o Colégio Centro Integrado de Educação Assis Chateaubriand, localizado na Rua Arivaldo de Carvalho, número 921, Sobradinho, Feira de Santana-BA.

\section{RESULTADOS E/OU DISCUSSÃO}

O patrimônio cultural rememora algo ou alguém que possui importância na história local ou no contexto histórico de um país, sua introdução no ensino de História deve ser dada utilizando a metodologia da educação patrimonial, que além de tornar as aulas mais atrativas e dinâmicas é possível também educar sobre a preservação do bem que está sendo estudado, relatando sobre a importância do mesmo na construção da história local, salvando e guardando informações sobre o bem cultural, descobrindo-o e preservando sua memória.

Durante o processo de observação da aplicação do Projeto Educação Patrimonial e Artista-EPA, fora analisado a contribuição do mesmo para a construção do saber histórico do Colégio Centro Integrado de Educação Assis Chateaubriand (CIEAC) para uma educação patrimonial sobre Feira de Santana-BA. Buscando identificar e refletir sobre os saberes dos docentes e discentes, sobre a história de Feira de Santana e a Educação Patrimonial.

O projeto Educação Patrimonial e Artística (EPA), desenvolvido na rede estadual de ensino, busca de fato tratar de experiências em políticas culturais com os estudantes no campo da educação patrimonial, buscando levar para dentro da escola o conhecimento sobre os espaços históricos das cidades, com vistas à identificação do patrimônio baiano, a preservação da memória cultural e a apropriação do conhecimento da história cultural baiana, na tentativa de consolidar a formação de uma nova mentalidade cultural. O EPA possibilita aos estudantes e professores o entendimento das distintas linguagens artísticas (visuais, fílmica, literária, musical, coreográfica). Que no cotidiano de sala de aula não tem sido devidamente trabalhado por professores, por priorizarem os conteúdos de caráter nacional e internacional, mais cobrados no ENEM e nos vestibulares. O projeto leva para o ambiente da escola os distintos tipos de patrimônio nos seus diversos contextos.

O conjunto de atividades (oficinas formativas sobre patrimônio, oficina de elaboração de trabalhos científicos, oficinas de fotografias e visitas guiadas aos 
patrimônios), que são desenvolvidas durante todo o período correspondente ao projeto na escola, possibilita que o estudante entre em contato com a história dos patrimônios locais, fotografias antigas e fotografias atuais dos patrimônios históricos, o que desperta nos mesmos amplos olhares diagnósticos sobre o patrimônio.

Durante a aplicação do projeto foi possível comprovar que de fato o Projeto EPA sensibiliza-se na escola e nos alunos, através das práticas de identificação e de preservação patrimonial, sobre a ótica estudantil. Isso porque os encontros com os grupos, sobre leituras e noções patrimoniais e fotográficas, assim como as visitações aos patrimônios de modo geral, contribuíram diretamente com a democratização dos saberes culturais dos estudantes sobre cada parte da cidade.

Porém, foi observado que a percepção dos professores relacionados à Educação Patrimonial e ao ensino de História no decorrer da aplicação do projeto foi bastante restrita ao patrimônio histórico material reconhecido e tombado por órgãos de preservação, não enfatizando os não tombados e os imateriais, além de não abrangerem muito como elas podem ser relacionadas no contexto diário das aulas. Tal fato se agrava à medida que esta preferência dos professores influencia diretamente nos alunos, o que acaba sendo um fato negativo nos resultados que o projeto deseja alcançar.

\section{CONSIDERAÇÕES FINAIS}

Compreender a contribuição do Projeto Educação Patrimonial e Artística (EPA) para a construção do saber histórico do Colégio Centro Integrado de Educação Assis Chateaubriand (CIEAC) e uma educação patrimonial sobre Feira de Santana-BA. Possibilitou reflexões sobre a aplicação do projeto de Educação Patrimonial e ArtísticoEPA, com base nos dados analisando, pode-se afirmar que trabalhar a Educação Patrimonial no contexto escolar é necessário e possível, mas precisa ir além dos projetos complementares\pontuais de educação, fazendo com que o aluno vivencie através dos conteúdos que são expostos em sala de aula, na rotina escolar, a história de seus bairros, cidades e país.

O patrimônio cultural é um dos elementos integrantes da construção da identidade social e cultural de uma sociedade, e a construção de conhecimento através da educação para o patrimônio proporciona aos estudantes autonomia na tomada de suas decisões, ajudando-os a tornarem-se cidadãos que entendem a importância da preservação e valorização do seu patrimônio, das suas culturas. Além de facilitar o ensino aprendizagem, os torna indivíduos mais críticos. O EPA fortalece esta ideia, quando mesmo coloca o aluno fora do ambiente da escola, para refletir sobre os patrimônios que vos cerca. 
Deste modo, há a necessidade de se trabalhar o Patrimônio Cultural nas escolas e fortalecer a relação das pessoas com suas heranças culturais, estabelecendo um melhor relacionamento das mesmas com estes bens, percebendo sua responsabilidade pela valorização e preservação do Patrimônio, fortalecendo a vivência real com a cidadania, num processo de inclusão social. Portanto, é necessário que a prática educativa esteja diretamente ligada à teoria e que haja uma conexão contínua entre os conteúdos “clássicos" e a educação patrimonial no espaço das aulas.

\section{REFERÊNCIAS}

1. ALVES-MAZZOTTI, Alda Judith; GEWADSZNJDER, Fernando. O método nas ciências naturais e sociais: pesquisa quantitativa e qualitativa. 2. ed. São Paulo: Pioneira, 2001. (Parte 2).

2. ENSINO DE HISTÓRIA: desafios contemporâneos / org. Véra Lucia Maciel Barroso...[etal]. - Porto Alegre: EST: EXCLAMAÇÃO: ANPUH/RS, 2010. 296 p.

3. ANDRÉ, Marli Eliza Dalmazo Afonso de. Etnografia da prática escolar. Campinas:

4. Papirus, 1995.

5. __ Avanços no conhecimento etnográfico da escola. In: FAZENDA, Ivani (Org.). A

6. Pesquisa em educação e as transformações do conhecimento. 2. ed. Campinas: Papirus,

7. 1997a.

8. _ Tendências atuais da pesquisa na escola. Cadernos CEDES, Campinas, v. 18, n. 43,p.1-9, dez. 1997.

9. HORTA, Maria de Lourdes Pereira. "Fundamentos da Educação Patrimonial" IN.: Revista da Faculdade Porto Alegrense de Educação, Ciências e Letras. Porto Alegre, RS, 2000.

10. SANTOS, Dário Tavares. Heranças e lembranças: educação, patrimônio cultural e

11. Desenvolvimento em Itaparica / Dário Tavares Santos. 2011.

12. TEIXEIRA, C. A. R.; A Educação Patrimonial no Ensino de História. Biblos (Rio Grande), v.22, p. 199-211, 2008. 